\title{
The Role of Collaborative Healthcare in Improving Social Sustainability: A Conceptual Framework
}

\author{
Tahereh Maghsoudi *, Rosalía Cascón-Pereira $(\mathbb{D})$ and Ana Beatriz Hernández Lara \\ Business Management Department, Faculty of Business and Economy, Universitat Rovira i Virgili, \\ 43204 Reus, Spain; rosalia.cascon@urv.cat (R.C.-P.); anabeatriz.hernandez@urv.cat (A.B.H.L.) \\ * Correspondence: tahereh.maghsoudi@urv.cat; Tel.: +346-6542-3026
}

Received: 16 January 2020; Accepted: 10 April 2020; Published: 15 April 2020

check for updates

\begin{abstract}
Healthcare systems around the world face both increasing demands and inequality in service distribution. The current trend is for collaboration among healthcare actors, named as collaborative healthcare, in order to address challenges such as these to improve the social sustainability of the system. That is to provide accessible and equitable healthcare services to meet people's health and well-being needs. Based on an integrative literature review, this study aims at crafting a conceptual framework to explore how collaborative healthcare networks contribute to social sustainability and the specific actors involved in these collaborations. It identifies relationships between different collaborative healthcare networks and social sustainability. Interprofessional networks have been the most studied in relation to social sustainability. Communication and sharing information or knowledge have been identified as used collaborative healthcare practices. This study contributes theoretically by considering a new model of the healthcare organization in which collaborative networks play a central role in improving social sustainability. In terms of practical implications, the study provides managers and policy makers with investment insights on a range of collaborative networks and practices.
\end{abstract}

Keywords: collaboration; collaborative healthcare; sustainability; social sustainability

\section{Introduction}

Globally, healthcare systems aim to provide services to promote, restore, and improve the health indicators of the population [1-3]. However, they do so in the context of facing multiple social challenges such as an unfair distribution of resources and increasing healthcare demands [4]. In this regard, social sustainability is seen as a key indicator of quality [5]. The growing body of research on the development of effective healthcare systems has placed greater emphasis on relevant policies and ethical implications and less on social sustainability issues [6]. There is little research on the organizational factors contributing to the development of social sustainability-oriented healthcare systems and it is crucial to explore more appropriate healthcare models embedding such principles.

Healthcare systems are identified by multiple players or stakeholders, including professionals (clinicians and non-clinical professions), managers, patients, providers of healthcare products, scientists, and governments/policy makers. The multi-stakeholder nature of healthcare systems highlights the need for a collaboration model. Shared interests among stakeholders need to be developed in defining different policies, strategies, and objectives. Social sustainability improvement represents an opportunity for aligning such interests. For multi-stakeholder institutions, collaboration implies greater credibility, commitment, accountability, support, and legitimacy of stakeholders. However, the healthcare literature shows that the culture of healthcare organizations suffers from low trust and limited collaboration at both professionals and organizational levels [7]. Collaborative healthcare has been introduced to address such challenges and improve the quality of care [8]. 
In particular, collaborative healthcare models contributes to sustainability development [9]. Sustainability has been acknowledged as a magnet [10] to pull healthcare stakeholders' interests together and commit them to the common goal of sustainability development. Although sustainability encompasses economic, social, and environmental (or ecological) dimensions [11], named as the triple bottom line, existing research in this highly relevant area has mainly been limited to the economic dimension [11], such as the impact of collaborative healthcare models on the financial performance. Although social sustainability is essential to the healthcare system, research on this dimension is relatively sparse and emerging [12]. Hence, this study aims to broaden this incipient research line by introducing collaborative healthcare as an alternative model for social sustainability improvement. To do so, we developed a conceptual framework based on a literature review of collaborative healthcare and social sustainability. In doing so, we explicitly focus on the social dimension of sustainability.

The paper is organized by first describing how the integrative literature review was conducted to construct the conceptual framework. Second, the conceptual framework is developed by reviewing the concept of collaborative healthcare and then proposing the relationship between different collaborative healthcare networks and social sustainability. We finally discuss the potential of this conceptual framework for developing further research in the area.

\section{Integrative Literature Review}

Our aim here was to contribute a final conceptual framework that related collaborative networks and social sustainability, thus making it appropriate to conduct an integrative literature review. The main purpose therein was to "revise, criticize, and synthesize the representative literature on a topic in an integrated way such that new frameworks and perspectives on the topic are generated" [13] (p. 357). Integrative literature reviews are mainly articulated for dynamic, mature, and new emerging topics with rapid growth [14], features that appear in the research line of social sustainability in healthcare systems [15].

Unlike the systematic literature review, the integrative literature review does not function on the basis of a prescribed methodology or standardized format for review [13,16]. In our case, we used Scopus and Web of Science databases for conducting the review. We also formulated our review around three key relevant bodies of literature in the context of healthcare, including social sustainability, social performance, and collaboration/participation practices.

In the same vein, we articulated our review around the relevant keywords exiting in the title, abstract, or keywords of publications. The following terms were used in the search: sustainability, social sustainability, social performance, corporate social responsibility (CSR), healthcare, collaborative/participative healthcare, collaborative/participative healthcare, collaborative/participative care, medical collaboration, collaboration, and collaborative/participative practices (e.g., communication). To identify relevant articles in the databases, we matched specific keywords (e.g., the terms collaborative healthcare* and participative health* were matched with sustainability, social sustainab*, social performance, and CSR).

The initial search of the keywords in both titles and abstracts identified 9813 articles. We subsequently narrowed the search to include only the key relevant literature bodies for the present study, which are social sustainability, social performance, collaborative/participative healthcare practices. Adopting these restrictions produced a database of 546 articles.

We only included what we considered relevant articles based on the following criteria:

- They should address one or more collaborative practices, such as communication and knowledge sharing.

- They should consider researches conducted in healthcare, business, and management.

- $\quad$ They should be written in English language

Based on the above procedures, the final dataset was composed of 45 articles. 


\section{Theoretical Background}

This section examines the literature related to collaborative healthcare and its practices, and the relationship between collaborative healthcare and social sustainability improvement. Also, a conceptual framework is explored to show how collaborative healthcare can contribute to social sustainability improvement.

\subsection{Collaborative Healthcare}

Change and revision of policies and approaches in healthcare systems to redesign traditional practices have been emphasized in order to improve the quality and effectiveness of healthcare $[8,17,18]$. For instance, enhancing knowledge exchange within a healthcare system [18], and ensuring its social sustainability [19] have been highlighted as cornerstones of new healthcare system models. Concepts such as teamwork, collaborative networks, and partnership have emerged [20].

Collaboration in healthcare refers to a coordinated team activity, in which members with various knowledge, skills, and capabilities work together to conduct a series of tasks for meeting the shared targets [21]. Wood and Gray [22](p. 146) indicated that collaboration "occurs when a group of autonomous stakeholders of a problem domain engages in an interactive process, using shared rules, norms and structures, to act or decide on issues related to that domain". The Institute of Medicine (IOM) offers a more comprehensive definition, when it mentions that collaborative healthcare is "designed to generate and apply the best evidence for the collaborative healthcare choices of each patient and provider; to drive the process of discovery as a natural outgrowth of patient care; and to ensure innovation, quality, safety, and value in healthcare" [23](p. 436).

More readily than traditional models of healthcare, collaborative healthcare can address the growing expectations of healthcare users [24] and current healthcare challenges, such as an increase in chronic diseases and population ageing, both of which require of greater collaboration among healthcare actors to be properly addressed [25].

The quality collaboration that brings together healthcare stakeholders to achieve common and improved objectives [26] is key for healthcare improvement. Collaboration may result in optimizing the development of resources, enhancing communication, coordination, and consequently a better healthcare performance [27]. Collaboration within different healthcare networks, such as professionals-patients, inter-professionals, leadership, and healthcare research, has been introduced as an innovative model to improve healthcare performance, considering different aspects such as social sustainability improvement [19] and comprehensive quality care $[8,17,28]$.

Notwithstanding the common agreement on the positive effects of collaborative models in healthcare, there is less agreement on what exactly collaborative practices consist of [29]. Communication among team members [21], sharing information [30], sharing experience, power and responsibility, involvement in decision-making process, and sharing resources [31] have all been highlighted. Wald et al. [30] proposed the Mayo Clinic model as an innovative and scalable model that shows the importance of collaboration in the development of quality of care. In their model, clinical collaboration emerges in the form of sharing information via technology and involves eConsults, the AskMayoExpert (AME), eBoard conferences, and healthcare consulting. On the other hand, Bourgeault and Mulvale [31] indicated that collaborative healthcare involves interdependent teams sharing power and responsibility. These different views on what collaboration is and, in particular, on what is shared through collaboration, whether it be merely information or also includes decision-making, responsibility, or power to accomplish these responsibilities, show the need for common ground or understanding in order to make the results of different models comparable.

Another relevant issue relates to who collaborates. Previous studies have identified different stakeholders involved in the healthcare system such as professionals (including clinicians such as nurses, medical doctors, physiotherapists, psychologists), and non-clinical professionals (such as accountants and administrative staff among others), managers, and patients, suppliers of healthcare products, healthcare scientists, and policy makers. The available studies have focused only on one or 
two stakeholders in defining the healthcare network. For instance, some research has focused on the role of patients in this network $[17,28]$. Another major stream of research refers to the collaboration between nurses and physicians [32,33]. Similarly, Buchanan [34] defined collaboration in this context as an interdependent association among different healthcare providers, including nurses, physicians, and other allied healthcare workers, who have a shared goal of providing quality patient care while having differing authorities and responsibilities. This view consequently excludes other actors such as scientists or policy makers.

These studies represent only a partial view of what collaborations and networks might be included in the healthcare sector. The collaboration among different actors results in the emergence of a wide range of possible healthcare networks, such as inter-professionals, professionals-patients, leadership, and research networks. Further clarification needs to be made in terms of what actors collaborate when referring to collaborative healthcare models. The consideration of a wider range of relevant actors, which might involve managers, clinical and non-clinical professionals, scientists, suppliers of healthcare products, political actors and patients will allow consideration of more and varied impacts of collaborative healthcare networks on social sustainability.

\subsection{Social Sustainability}

The ever-changing lifestyles and conditions have long constituted the importance of not only natural but also social sustainability because health and safety status of people are affected by both environmental and social factors and a community must prioritize the health and safety of its population to sustain itself [35]. Having the focus of majority of previous research on the role of unhealthy environmental factors in sustaining communities, human health also depends on social matters [35].

Due to the notion that it constitutes the forerunner for environmental sustainability, the concept of social sustainability has been under-theorized [36] in sustainability literature [37]. Recently, however, there have been a few attempts to introduce social sustainability as an independent component [36]. Three main approaches can be identified in social sustainability; (1) social sustainability as equal to environmental sustainability; (2) social sustainability as an environmental-oriented factor referring to a necessary precondition for meeting environmental sustainability; (3) social sustainability as a people-oriented dimension which emphasizes the wellbeing of individuals and the fair distribution of resources [38]. Given the characteristics of the healthcare context, in which the concept of social sustainability is explored, the third, people-oriented approach is judged as the most appropriate. In particular, because this context implies both the improvement of the wellbeing of patients and employees and the need for justice in the distribution of resources, so the people-oriented dimension of social sustainability becomes key in this context.

In the sustainability literature, the terms social performance and social sustainability are sometimes applied interchangeably [39]. Given that there is not a singular definition for social sustainability in the literature [40], the concept can refer to key themes that embody social issues relevant to sustainability, such as access to basic needs [41], social justice [42], and equity [43]. In this regard, a system is sustainable when a wide range of human needs are addressed in a way that secures its nature and its regenerative abilities over time, considering committing to social justice, human dignity, and engagement [44]. Social sustainability emphasizes the human side of sustainability involving human rights, and health and safety $[15,45]$. Social sustainability relates to "something human beings value, strive for or hope to attain" [46] (p. 75).

Therefore, to address social sustainability in the healthcare context, a healthcare system must provide sufficient resources and activities to meet individual and public health needs [47]. Social sustainability in the healthcare context has been defined as a "process of creating an accessible, integrated and equitable community that successfully meets the needs of health and well-being of users" [48] (p. 16). Similarly, Awan et al. [39] indicated that social sustainability implies both the fair distribution of health and safety resources and providing equal opportunities to access these resources. 
These objectives of social sustainability in healthcare systems may secure the survival of a healthcare system as they address the expectations of stakeholders.

Social sustainability can result in a chain of interconnected positive outcomes. For instance, it may enhance individuals' satisfaction [49] and satisfied individuals would feel more commitment and be more willing to share their knowledge in an organization [50], which in turn can develop sustainable performance [51]. In a similar way, social sustainability may shape the perceived organizational support (POS) among individuals in healthcare system as its key concern, like POS [52], is valuing individuals through fair distribution of care facilities and promotion of well-being $[39,48]$. When employees perceive organization care about them, their organizational identification might increase and this can develop their collaboration, task performance, and extra-role helping behavior, namely organizational citizenship behaviors (OCB) [53]. Quality of performance and OCB are the key in healthcare systems that are people-oriented and play a significant role in providing and securing health and safety of communities.

Given the sparsity of theoretical and empirical studies concerning social sustainability in the healthcare context [15], existing studies have introduced different indicators to evaluate it (Table 1). For instance, Capolongo et al. [48] identified safe and security, wellbeing, health promotion, accessibility, and fair distribution, and quality of relationships as the main indicators of social sustainability in healthcare.

Table 1. Social sustainability indicators in healthcare context.

\begin{tabular}{cc}
\hline Indicators & Relevant Studies \\
\hline Professionals' wellbeing, safety, security, satisfaction & Capolongo et al. [48], Chiu [38] \\
\hline $\begin{array}{c}\text { Professionals' comfort (daylighting, social thermal } \\
\text { comfort, acoustic, and indoor air quality) }\end{array}$ & Capolongo et al. [48] \\
\hline $\begin{array}{c}\text { Patients' accessibility to healthcare and fair } \\
\text { distribution }\end{array}$ & $\begin{array}{c}\text { Awan et al. [39], Capolongo et al. [48], Chiu [38], } \\
\text { Capolongo et al. [54] }\end{array}$ \\
\hline Patients' satisfaction & Faezipour and Ferreira [55] \\
\hline
\end{tabular}

Accordingly, Malby et al. [8] claimed that a high-performance collaborative healthcare system needs to involve the concept of social sustainability in its practices and approaches. Hence, social sustainability is also a shared concern of healthcare actors, which promotes collaboration among them [9,10,30,56-59]. It has been considered as a collaboration magnet among different actors, enhancing their collaborative spirit and behaviors [10]. Similarly, Khayatzadeh-Mahani et al. [9] pointed out that multi-actors collaboration is a crucial contributor to equity and quality of health at the social level, and this, in turn, shows that social sustainability plays the role of a magnet for collaboration among the different actors of the health system. Similarly, Wald et al. [30] proposed a collaborative healthcare model, namely the Mayo Clinic model. Their model proved that working collaboratively with a network of physicians can result in social sustainability development. From a different approach, Browning et al. [57] indicated that the collaborative leadership style can contribute to sustainability development. This leadership style implies a collective activity rather than an individual activity, where all members of a network share the leadership responsibility to fulfil the mission. They introduced it as a powerful means of attaining social sustainability since it contributes to reducing resistance and exploring new directions, opportunities, and alternatives which finally exert a positive impact on the healthcare system, in terms of quality. Along the same lines, Okpala [58] investigated collaborative leadership as a means of enhancing the quality of care. He found that the patient-centered and inter-organizational collaboration strategies promoted by collaborative leadership are cost-effective without having a negative effect on the quality of care. His results substantiated the thesis that collaborative leadership in healthcare can improve social sustainability, finding that health services become more affordable and consequently more accessible to patients. 


\subsection{Collaborative Healthcare and Social Sustainability}

Collaboration contributes to expanding more sustainable behaviors or approaches, long-term survival, and providing adequate skills and resources for improving social sustainability performance [60]. Social sustainability and collaborative healthcare are concepts that interact [9]. To some extent, they follow common grounds in terms of improving the health level of individuals, accessibility of healthcare services, and share the same objective which is continuing or improving health benefits or outcomes for healthcare system users [5,6,61,62]. For instance, the Institute of Medicine (IOM) [23] indicated that ensuring the quality, safety and value in healthcare are the aims of collaborative healthcare, and these objectives are in line with social sustainability objectives, in terms of wellbeing. Indeed, the concept of collaboration seems key in developing the "accessible, integrated, and equitable community" where people benefit from both current and future emotional-physical inclusion [54]. This also confirms addressing social sustainability objectives through collaboration aims. Similarly, Capolongo et al. [48] indicated collaboration is one of the means to obtain social sustainability objectives.

Collaboration within the healthcare network may address all social sustainability indicators through its practices; it involves communication [21], sharing resources and information [63], shared responsibility, cooperation, and trust [64]. These characteristics of collaboration improve health and safety indicators, and the availability of different types of resources. Quality communication, as a form of collaboration, can facilitate the process of sharing information, knowledge, experience, and resources among stakeholders and then this can improve the quality of care and the accessibility of care services for patients. For instance, Vuong et al. [35] showed that quality communication provides patients with more medical information, both in quality and quantity, and this results in enhanced user wellbeing. Furthermore, if user needs were explored, the healthcare system would be better able to fulfill them. Collaboration among stakeholders is fundamental in ensuring that their disparate needs are identified and addressed [48]. In a similar way, hospitals can communicate to share their resources and facilitate the referral process of patients to avoid negative consequences caused by delay treatment such as double transfer, and extra burden [65]. Consequently, collaboration is an essential characteristic of the improvement of social performance (social sustainability) of the healthcare system.

Patient satisfaction is identified as the key indicator for social sustainability, as it involves the well-being of the patient, quality of services, efficiency of staff, and the availability of resources [55]. However, previous research seems to have been more focused on exploring legislative issues or legal and political rights when addressing social sustainability [66]. As Hussain et al. [15] has already identified, there is a need to explore what makes a healthcare system more socially sustainable, particularly from the patients' perspective as they are the main customers of the healthcare system. Involvement of patients in collaborative models will result in higher service quality and greater satisfaction of both patients and professionals $[17,28]$. Along similar lines, Greenfield et al. [67] found that collaboration among patients and professionals through communication, shared information, and joint decision making enhances wellbeing, satisfaction, and knowledge, particularly in the case of chronic care [68]. They indicated that professionals and patients may collaborate in all steps of the decision-making process, from sharing treatment preferences to reaching agreement on a common treatment. Such involvement of patients in healthcare can increase their engagement with the treatment process and, as a result, their satisfaction. In addition, sharing information between patients and professionals can add value, for not only for the patients, but also for the professionals [69]. Professionals are provided with complementary information allowing them to identify more effective treatments and expand their knowledge and experience. Therefore, the following proposition emerges:

Proposition 1. Collaborative healthcare model, through the collaborative network between patients and professionals, can contribute to social sustainability improvement in healthcare. 
Collaboration among other stakeholders contributes to the development of social sustainability. For example, inter-professional collaboration enhances social sustainability. This type of collaboration adds value not only for professionals, but also for patients as a quality collaboration among professionals improves the quality of caring services and consequently the satisfaction of both patients and professionals [70,71]. Inter-professional collaboration allows these professionals to "work cooperatively, share responsibility for problem solving, address conflict management, perform joint decision-making and use open communication" [72] (p. 1) as well as share their knowledge and experience [30]. In the same vein, inter-professional collaboration results in more efficient access to specialist services and sources of new knowledge and experience [73], which, in turn, expand the experience, knowledge, and specialties of professionals and contribute to their satisfaction. So, collaborative practices may improve the social performance of healthcare; firstly for patients [71] who may receive services that have been improved by professional collaborations. Secondly, for professionals as healthcare employees, who will feel more engagement and satisfaction from their consequent professional growth. In this regard, we advance the following proposition:

Proposition 2. Collaborative healthcare model, through the collaborative network among professionals, can contribute to social sustainability improvement in healthcare.

Similarly, collaboration among scientists working jointly to see the issues from different angles may contribute to social sustainability improvement in healthcare. They may share their knowledge and then different scientific techniques, and views can be combined to address the issues more effectively [74]. Previous studies find that collaboration in clinically-oriented research has contributed to resolving health-related challenges and finding diagnostic criteria, improved treatment, care and preventive alternatives, and enhancement of standards and policies in healthcare [74,75]. For instance, $\mathrm{Gu}$ et al. [75] emphasized the need for collaboration among researchers to explore the prevalence of diagnosed and undiagnosed diabetes. Their findings contribute to health enhancement as the presence of diabetes increases the risk of other chronic diseases, such as vascular complications, and consequently, results in a considerable economic burden. In addition, collaboration among researchers may result in not only the improvement of current treatment methods or drugs but also the development of new ones which, in turn, improves not only the quality of services but also the accessibility and availability of healthcare resources. Thus, collaboration among scientists results in improvements in the social sustainability of healthcare, namely wellbeing, availability of resources, and satisfaction. In this regard, we propose:

Proposition 3. Collaborative healthcare model, through the collaborative network among scientists, can contribute to social sustainability improvement in healthcare.

Together with multidisciplinary collaboration (namely inter-professional collaboration and collaboration among scientists), transdisciplinary collaboration seems to be key for the development of social sustainability. The involvement of authorities, including policy-makers, managers, and professionals [76], in collaborative healthcare models results in the delivery of higher quality care services [77] as they can verify the possibility and applicability of the views proposed by professionals or scientists to the real world. In the same vein, Dabelko [78] (p. 1) indicated that "if the field is to have the kind of effects on the real world that it has always sought, it must move toward a more serious engagement with policy-makers." In addition, since they have the main responsibility and authority for this objective, policy makers and managers can set rules to ensure and even facilitate the implementation of the proposed views [79].

Furthermore, policy makers and managers can collaborate to establish a supportive environment contributing to the productivity and effectiveness of healthcare professionals. Al-Dweik et al. [80] pointed out that collaboration among policy makers and managers is key in the development of an empowering environment that contributes to enhancing a nurse's productivity. Similarly, policy 
makers and managers can work to facilitate the implementation of collaborative practices among other stakeholders. For instance, managers and policy makers can facilitate communication between professionals through the application of structural tools for communication [81]. A network of authorities, including policy makers, managers, and professionals [76] can contribute to social sustainability development, thus suggesting the next proposition:

Proposition 4. Collaborative healthcare model, through the collaborative network among managers, policy makers, and healthcare professionals, can contribute to social sustainability improvement in healthcare.

Inter-organizational collaboration also constitutes a type of collaboration that contributes to developing social sustainability in healthcare. It contributes to the availability of medical resources through sharing resources [82] and knowledge between professionals [58]. This type of collaboration contributes to social sustainability improvement by enhancing the availability of resources and maintaining the quality of care [58]. Inter-hospital collaboration, which may include patient sharing, provides patients with higher quality care [82]. Patients benefit from this opportunity to transfer from lower to higher quality hospitals with better resources. In this regard, inter-organizational collaboration is highly recommended to increase social sustainability in health systems as suggested in the next proposition:

Proposition 5. Collaborative healthcare model, through the collaborative network among healthcare organizations, can contribute to social sustainability improvement in healthcare.

A multi-disciplinary collaborative network of healthcare scientists, suppliers of healthcare products, and healthcare professionals may result in increased satisfaction for both professionals and patients. The stakeholders can collaborate to see the health-related issues from different views in order to explore/uncover more efficient alternatives in the form of technology or theory. This, in turn, enhances the quality of treatment methods as well as the availability of healthcare services, reduces harmful practices, and consequently results in social sustainability improvements. The specialties of professionals may also expand because of their sharing different views, which results in increased job satisfaction. For example, it has been found that the involvement of suppliers of products and services in a collaborative model can result in higher social sustainability performance as they share knowledge, and work jointly to create value and improve social performance [83-85]. Therefore, the next proposition can be advanced:

Proposition 6. Collaborative healthcare model, though the collaborative network among healthcare professionals, scientists and suppliers of healthcare products, can contribute to social sustainability improvement in healthcare.

Table 2 shows the summary of the collaborative networks and the collaborative practices which might be used in each network to develop social sustainability. In addition, it refers to some relevant studies whose results directly support, or which can be regarded as supporting evidence for, our propositions. Figure 1 also illustrates the propositions of study in a conceptual framework. 
Table 2. Collaborative networks and practices contributing to social sustainability in healthcare context.

\begin{tabular}{|c|c|c|}
\hline Collaborative Networks & Collaborative Practices & Relevant Studies \\
\hline Patients-professionals & $\begin{array}{l}\text { communication, sharing information, } \\
\text { shared decision making }\end{array}$ & $\begin{array}{c}\text { Ahgren and Axelsson [28], Doyle } \\
\text { et al. [17], Greenfield et al. [67], } \\
\text { Joosten et al. [69] }\end{array}$ \\
\hline Inter-professionals & $\begin{array}{l}\text { shared responsibility, joint decision } \\
\text { making, communication, shared } \\
\text { knowledge and experience, cooperative } \\
\text { work, conflict management and shared } \\
\text { problem solving }\end{array}$ & $\begin{array}{l}\text { Bartunek [70], Fisher et al. [71], } \\
\text { Nair et al. [56], Wald et al. [30], } \\
\text { Berendsen et al. [73] }\end{array}$ \\
\hline Scientists- scientists & Sharing knowledge and view & Raza [74], Gu et al. [75] \\
\hline $\begin{array}{l}\text { Managers-policy } \\
\text { makers-professionals }\end{array}$ & $\begin{array}{l}\text { sharing knowledge, view, power and } \\
\text { responsibility, and joint decision making }\end{array}$ & $\begin{array}{l}\text { Boswell et al. [77] Dabelko [62] } \\
\text { Al-Dweik et al. [80], } \\
\text { Wang et al. [81] }\end{array}$ \\
\hline Inter-organizational & $\begin{array}{l}\text { sharing resources and sharing } \\
\text { knowledge }\end{array}$ & Lomi et al. [82], Okpala [58] \\
\hline $\begin{array}{c}\text { Professionals-scientists-supplier of } \\
\text { healthcare products }\end{array}$ & $\begin{array}{l}\text { sharing knowledge, communication, } \\
\text { cooperative work }\end{array}$ & $\begin{array}{c}\text { Awan [84], Awan et al. [85], } \\
\text { Sancha et al. [83] }\end{array}$ \\
\hline
\end{tabular}

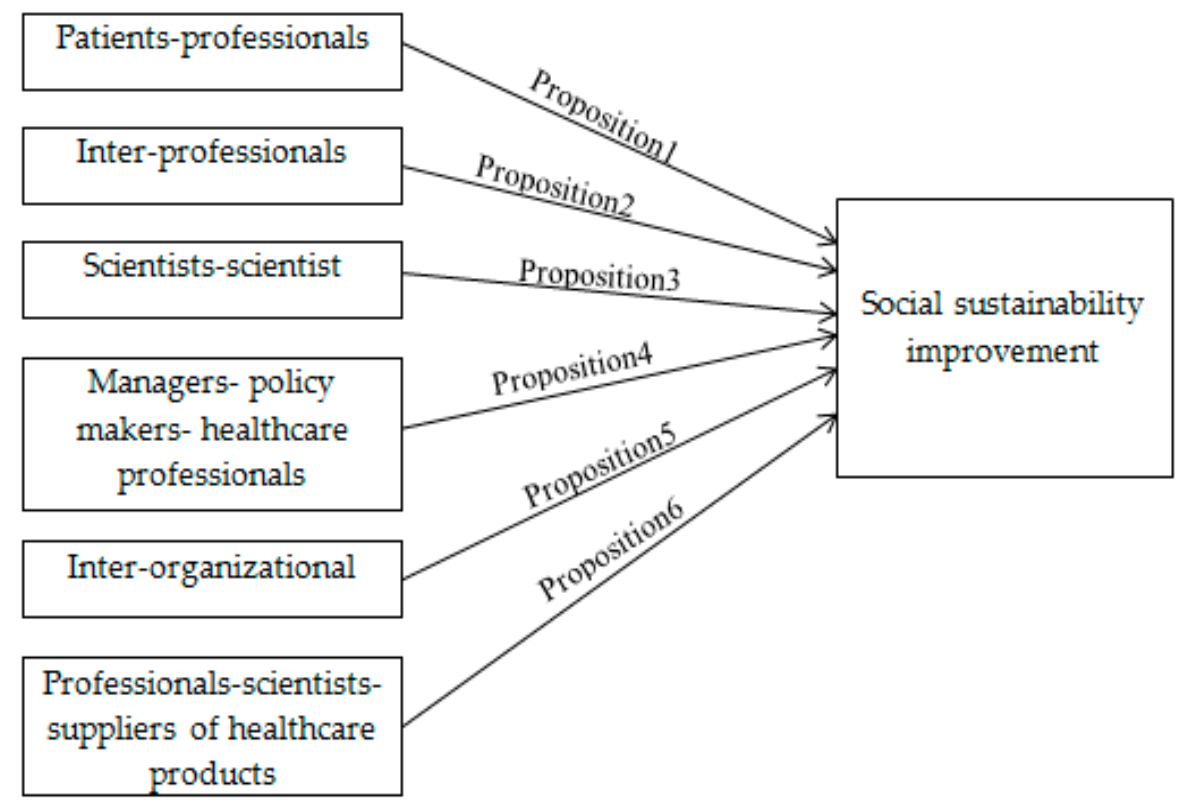

Figure 1. Conceptual framework of the study.

\section{Discussion and Conclusions}

This study has aimed at improving our understanding of the relationships between collaborative healthcare and social sustainability improvement. To do so, it has identified what collaborative networks exist in the healthcare context. On the other, however, it has explored what these networks share. In other words, it has explored what collaborative practices these networks can contribute to improving social sustainability (Table 2). Accordingly, we have developed six propositions relating to the collaborative networks that exist in the healthcare context and their potential contribution to social sustainability, as a starting point or a roadmap for developing further empirical research. This constitutes the major theoretical contribution of this conceptual paper. Future empirical research should test the validity of these propositions.

Although previous research has emphasized the importance of economic and environmental sustainability in the healthcare context, social sustainability has been less analyzed $[15,39,48]$. This scant attention to social sustainability may be due to considering social sustainability as the forerunner for other sustainability dimensions, namely environmental sustainability, and ignoring its independent 
characteristics [37]. Despite the interrelationships among the three dimensions of sustainability in healthcare systems, since the system is people-based and people-oriented, social sustainability needs in consequence to be regarded independently. In this regard, this study has contributed to the scarce literature on the relationship between collaborative networks and social sustainability in healthcare by setting the basis for conducting further empirical research based on the proposed conceptual framework.

Drawing on previous studies in the healthcare context, we have identified six collaborative networks (Figure 1) that can contribute to developing a social sustainable-oriented healthcare system. Of these, the collaborative network among healthcare professionals, especially among clinicians, is the one which holds more evidence in the literature to contribute to social sustainability improvement [86]. To support this, Reeves et al. [86] indicated that the importance of inter-professional collaboration stems from the complexity and multidimensional nature of patients' health and care requirements. Therefore, inter-professional collaboration may play a key role in the provision of a social sustainable healthcare system, with an increased patients and professionals' long-term wellbeing. However, to the best of our knowledge, the majority of previous studies have been limited to the collaboration between physicians and nurses $[33,87]$ while potential collaborations among other clinical professionals seem largely to be ignored. For instance, collaboration between cosmetic surgeons and psychologists can be explored for developing social sustainability through enhancement of the health, safety, and wellbeing of patients. Narcissistic and histrionic personality disorders and body dysmorphic disorder are the main motivation among patients seeking cosmetic surgery [88]. Such patient groups are more likely to repeat cosmetic surgery or become addicted to other cosmetic surgeries [89], and this can have a negative impact on their health [90]. Therefore, these possible collaborations among clinicians need to be explored in relation to patients' long-term wellbeing as a key indicator of social sustainability. Similarly, in our framework, collaboration networks between scientists, between scientists and policy makers, and even between scientists and patients are suggested to enhance social sustainability. For instance, scientists can collaborate together, they can communicate and share their knowledge to study the health-related challenges from different scientific views, and then combine them to propose potentially more effective alternatives to increase patients' wellbeing [74]. Moreover, a collaboration network including healthcare professionals and scientists can improve patients' wellbeing and satisfaction, through discovering more effective treatment methods or improving the accessibility of people to healthcare knowledge through offering a new model of healthcare system such as e-health. Furthermore, together with this multidisciplinary collaboration, collaboration between scientists and policy makers and managers (transdisciplinary) seems to be crucial in verifying the real world feasibility and applicability of any views proposed by scientists [78]. We therefore suggest further research to explore the potential role of other stakeholders in social sustainability development.

Since they appear in all collaborative networks (Table 2), communication and the sharing of information are suggested as the basic and primary collaborative practices. Communication constitutes the main precursor for other collaborative practices of sharing resources, information, and understanding [21].

In conclusion, with the proposed conceptual framework, this study has offered a roadmap for conducting future empirical research to test the propositions.

Furthermore, this study offers some practical considerations. First, hospital managers should appreciate and promote the crucial role of collaboration in developing patients' and professionals' long-term wellbeing. Despite differences on the meaning of collaboration and how might one collaborate, our conceptual study suggests that collaborative healthcare systems, as compared to traditional healthcare, are better at developing social sustainability. Communication, sharing information, and joint decision making, are the main collaborative practices identified. Quality communication develops transparency in relationships and is a key to successful collaboration; it is also a necessity for other collaborative practices such as shared decision making [69]. A collaborative network aims at seeing issues from different perspectives and finding the most efficient alternatives to tackle issues, so sharing 
information is a basis for benefiting from collaborative networks. Therefore, development of the effectiveness of such practices through investment in their pre-requisites, such as trust and openness, is recommended.

Second, the collaboration among health professionals is crucial to the performance of the healthcare system [91] and especially for social sustainability objectives. Therefore, developing collaborative networks between them is recommended. Since the healthcare system is a multi-stakeholder system, we recommend the involvement of all stakeholders in collaborative networks to increase its social sustainability. The involvement of policy makers is also a notable instance. Since they have the authority and power to set or control the laws [76], they can work with other stakeholders, e.g., managers and professionals, to identify and set the alternatives to facilitate accessibility of rare healthcare services for anyone regardless of their geographical location or economic group.

This study is not without limitations. This study was conducted on the basis of an integrative literature review, which is not based on prescribed methodology or standardized format $[13,16]$. In this vein, due to the importance of this research line and its fast growth, further systematic literature reviews could complement and provide additional insights on the topic. This study is also a conceptual study which makes six propositions emerging from the literature review on which it is based. However, further empirical research should test the validity of these propositions, thus helping to determine the applicability of collaborative healthcare in improving social sustainability in the healthcare context. Furthermore, the propositions should be operationalized with appropriate indicators in further research.

Author Contributions: Conceptualization, T.M., R.C.-P., and A.B.H.L.; validation, T.M., R.C.-P., and A.B.H.L.; investigation, T.M., R.C.-P., and A.B.H.L.; resources, T.M., R.C.-P., and A.B.H.L.; writing-original draft preparation, T.M., R.C.-P., and A.B.H.L.; writing-review and editing, T.M., R.C.-P., and A.B.H.L.; visualization, T.M., R.C.-P., and A.B.H.L.; supervision, T.M., R.C.-P., and A.B.H.L. All authors have read and agreed to the published version of the manuscript.

Funding: This research has received funding from the European Union's Horizon 2020 research and innovation programme under the Marie Skłodowska-Curie grant agreement No. 713679 and from the Universitat Rovira i Virgili (URV).

Conflicts of Interest: The authors declare no conflict of interest.

\section{References}

1. Roussos, S.T.; Fawcett, S.B. A Review of Collaborative Partnerships as a Strategy for Improving Community Health. Annu. Rev. Public Health 2000, 21, 369-402. [CrossRef]

2. Singh, P. Lean in healthcare organization: an opportunity for environmental sustainability. Benchmarking 2019, 26, 205-220. [CrossRef]

3. Mishra, R.K.; Sarkar, S.; Singh, P. Today's HR for a sustainable tomorrow; Allied Publishers: New Delhi, India, 2012; ISBN 9788184247541.

4. Bernal-delgado, E. La calidad del Sistema Nacional de Salud: base de su deseabilidad y sostenibilidad The quality of the National Health System: basis for its desirability and sustainability. Gac. Sanit. 2010, 24, 254-258. [CrossRef] [PubMed]

5. Shelton, R.C.; Cooper, B.R.; Stirman, S.W. The Sustainability of Evidence-Based Interventions and Practices in Public Health and Health Care. Annu. Rev. Public Health 2018, 39, 55-76. [CrossRef]

6. Scheirer, M.A.; Dearing, J.W. An Agenda for Research on the Sustainability of Public Health Programs. Am. J. Public Health 2011, 101, 2059-2067. [CrossRef]

7. Mitchell, R.; Parker, V.; Giles, M.; White, N. Review: Toward realizing the potential of diversity in composition of interprofessional health care teams: an examination of the cognitive and psychosocial dynamics of interprofessional collaboration. Med. Care Res. Rev. 2010, 67, 3-26. [CrossRef]

8. Malby, R.; Amoo, N.; Mervyn, K. Innovation and sustainability in a large-scale healthcare improvement collaborative-seven propositions for achieving system-wide innovation and sustainability. Int. J. Sustain. Strateg. Manag. 2016, 5, 149-179. 
9. Khayatzadeh-Mahani, A.; Labonté, R.; Ruckert, A.; de Leeuw, E. Using sustainability as a collaboration magnet to encourage multi-sector collaborations for health. Glob. Health Promot. 2019, 26, 100-104. [CrossRef] [PubMed]

10. Béland, D.; Cox, R.H. (Eds.) Ideas and Politics in Social Science Research; Oxford University Press: London, UK, 2010; ISBN 9780199736430.

11. Boyer, R.H.W.; Peterson, N.D.; Arora, P.; Caldwell, K. Five Approaches to Social Sustainability and an Integrated Way Forward. Sustainability 2016, 8, 878. [CrossRef]

12. Borgonovi, E.; Compagni, A. Sustaining Universal Health Coverage: The Interaction of Social, Political, and Economic Sustainability. Value Heal. 2013, 16, S34-S38. [CrossRef] [PubMed]

13. Torraco, R.J. Writing Integrative Literature Reviews: Guidelines and Examples. Hum. Resour. Dev. Rev. 2005, 4, 356-367. [CrossRef]

14. Torraco, R.J. Writing Integrative Literature Reviews: Using the Past and Present to Explore the Future. Hum. Resour. Dev. Rev. 2016, 1-25.

15. Hussain, M.; Ajmal, M.M.; Gunasekaran, A.; Khan, M. Exploration of social sustainability in healthcare supply chain. J. Clean. Prod. 2018, 203, 977-989. [CrossRef]

16. Jesson, J.; Matheson, L.; Lacey, F.M. Doing Your Literature Revie-Traditional and Systematic; SAGE: London, UK, 2011; ISBN 9781848601543.

17. Doyle, C.; Howe, C.; Woodcock, T.; Myron, R.; Phekoo, K.; McNicholas, C.; Saffer, J.; Bell, D. Making change last: applying the NHS institute for innovation and improvement sustainability model to healthcare improvement. Implement. Sci. 2013, 8, 127. [CrossRef] [PubMed]

18. Scott, C.M.; Thurston, W.E. A framework for the development of community health agency partnerships. Can. J. Public Heal. 1997, 88, 416-420. [CrossRef]

19. Touati, N.; Rodríguez, C.; Paquette, M.A.; Denis, J.L. Understanding the emergence and development of medical collaboration across organizational boundaries: A longitudinal case study. Heal. (United Kingdom) 2018, 22, 580-602. [CrossRef] [PubMed]

20. Scott, C.M.; Thurston, W.E. The Influence of Social Context on Partnerships in Canadian Health Systems. Gender, Work Organ. 2004, 11, 481-505. [CrossRef]

21. Patel, V.L.; Cytryn, K.N.; Shortliffe, E.H.; Safran, C. The Collaborative Health Care Team: The Role of Individual and Group Expertise. Teach. Learn. Med. 2000, 12, 117-132. [CrossRef]

22. Wood, D.J.; Gray, B. Toward a Comprehensive Theory of Collaboration. J. Appl. Behav. Sci. 1991, 27, $139-162$. [CrossRef]

23. Smith, M.; Saunders, R.; Stuckhardt, L.; Mcginnis, J.M.; Care, H. Best Care at Lower Costo: The Path to Continuously Learning; National Academies Press: Washington, DC, USA.

24. Elpern, E.; Rodts, M.; DeWald, R.; West, J. Associated practice: a case for professional collaboration. J. Nurs. Adm. 1983, 13, 27-31. [CrossRef]

25. Knowles, S.E.; Chew-Graham, C.; Coupe, N.; Adeyemi, I.; Keyworth, C.; Thampy, H.; Coventry, P.A. Better together? a naturalistic qualitative study of inter-professional working in collaborative care for co-morbid depression and physical health problems. Implement. Sci. 2013, 8, 110. [CrossRef] [PubMed]

26. Rossiter, M.; Verma, J.; Denis, J.; Samis, S.; Wedge, R.; Power, C. Governing collaborative healthcare improvement: lessons from an Atlantic Canadian case. Int. J. Heal. Policy Manag. 2017, 6, 691-694. [CrossRef]

27. Braithwaite, J.; Vincent, C.; Nicklin, W.; Amalberti, R. Coping with more people with more illness. Part 2: new generation of standards for enabling healthcare system transformation and sustainability. Int. J. Qual. Heal. Care 2018, 31, 159-163. [CrossRef] [PubMed]

28. Ahgren, B.; Axelsson, R. A decade of integration and collaboration: the development of integrated health care in Sweden 2000-2010. Int. J. Integr. Care 2011, 11. [CrossRef] [PubMed]

29. Huerta, T.; Casebeer, A.; Vanderplaat, M. Using networks to enhance health services delivery: perspectives, paradoxes and propositions. Heal. Pap 2006, 7, 10-26. [CrossRef] [PubMed]

30. Wald, J.T.; Lowery-Schrandt, S.; Hayes, D.L.; Kotsenas, A.L. Mayo Clinic Care Network: A Collaborative Health Care Model. J. Am. Coll. Radiol. 2018, 15, 167-172. [CrossRef]

31. Bourgeault, I.L.; Mulvale, G. Collaborative health care teams in Canada and the USA: Confronting the structural embeddedness of medical dominance. Heal. Sociol. Rev. 2006, 15, 481-495. [CrossRef]

32. Zwarenstein, M.; Bryant, W. Interventions to promote collaboration between nurses and doctors. Cochrane Database Syst. Rev. 2000, CD000072. 
33. Caricati, L.; Guberti, M.; Borgognoni, P.; Prandi, C.; Spaggiari, I.; Vezzani, E.; Iemmi, M. The role of professional and team commitment in nurse-physician collaboration: A dual identity model perspective. J. Interprof. Care 2015, 29, 464-468. [CrossRef]

34. Buchanan, L. The Acute Care Nurse Practitioner in Collaborative Practice. J. Am. Acad. Nurse Pract. 1996, 8 , 13-20. [CrossRef]

35. Vuong, Q.H.; Vuong, T.T.; Ho, T.M.; Nguyen, H.V. Psychological and socio-economic factors affecting social sustainability through impacts on perceived health care quality and public health: The case of Vietnam. Sustainability 2017, 9, 1456. [CrossRef]

36. Colantonio, A. Social sustainability: a review and critique of traditional versus emerging themes and assessment methods. In Proceedings of the Second International Conference on Whole Life Urban Sustainability and Its Assessment: Conference Proce; Loughborough University: Loughborough, UK, 2009; pp. 865-885.

37. Hardoy, J.; Mitlin, D.; Satterthwaite, D. Environmental problems in Third World cities.; Routledge: London, UK, 1992; ISBN 1853831468.

38. Chiu, R.L.H. Social Sustainability, Sustainable Development and Housing Development: The Experience of Hong Kong. In Housing and Social Change: East-West Perspectives; Chapter 12; Forrest, R., Lee, J., Eds.; Routledge: London, UK; New York, NY, USA, 2003; pp. 233-251.

39. Awan, U.; Kraslawski, A.; Huiskonen, J. Governing interfirm relationships for social sustainability: the relationship between governance mechanisms, sustainable collaboration, and cultural intelligence. Sustainability 2018, 10, 4473. [CrossRef]

40. Granovetter, M.S. The Strength of Weak Ties. Am. J. Sociol. 1973, 78, 1360-1380. [CrossRef]

41. Fine, B. Social capital vs social theory; Routledge: London, UK, 2001; ISBN 9780415241809.

42. Avery, S.L.; Swafford, P.M. Social Capital Impact On Service Supply Chains. J. Serv. Sci. 2009, 2, 9-16. [CrossRef]

43. Min, S.; Kim, S.K.; Chen, H. Developing social identity and social capital for supply chain management. J. Bus. Logist. 2008, 29, 283-304. [CrossRef]

44. Konovsky, M.A.; Pugh, S.D. Citizenship Behavior and Social Exchange. Acad. Manag. J. 1994, 37, 656-669.

45. Anisul Huq, F.; Stevenson, M.; Zorzini, M. Social sustainability in developing country suppliers. Int. J. Oper. Prod. Manag. 2014, 34, 610-638. [CrossRef]

46. Thompson, P.B. Sustainability as a Norm. Techné Res. Philos. Technol. 1997, 2, 99-110. [CrossRef]

47. Oslen, I.T. A framework for analyzing sustainability. Heal. Pol. Plann 1998, 13, 3-287.

48. Capolongo, S.; Gola, M.; Di Noia, M.; Nickolova, M.; Nachiero, D.; Rebecchi, A.; Settimo, G.; Vittori, G.; Buffoli, M. Social sustainability in healthcare facilities: a rating tool for analysing and improving social aspects in environments of care. Ann Ist Super Sanità 2016, 52, 15-23.

49. Masocha, R. Social Sustainability Practices on Small Businesses in Developing Economies: A Case of South Africa. Sustainability 2019, 11, 3257. [CrossRef]

50. Cugueró-Escofet, N.; Ficapal-Cusí, P.; Torrent-Sellens, J. Sustainable human resource management: How to create a knowledge sharing behavior through organizational justice, organizational support, satisfaction and commitment. Sustainability 2019, 11, 5419. [CrossRef]

51. Jilani, M.M.A.K.; Fan, L.; Islam, M.T.; Uddin, M.A. The Influence of Knowledge Sharing on Sustainable Performance: A Moderated Mediation Study. Sustainability 2020, 12, 908. [CrossRef]

52. Eisenberger, R.; Huntington, R.; Hutchison, S.; Sowa, D. Perceived organizational support. J. Appl. Psychol. 1986, 71, 500-507. [CrossRef]

53. Shen, J.; Benson, J. When CSR is a social norm: how socially responsible human resource management affects employee work behavior. J. Manage. 2014, 42, 1723-1746. [CrossRef]

54. Capolongo, S.; Buffoli, M.; Oppio, A.; Rizzitiello, S. Measuring hygiene and health performance of buildings: a multidimensional approach. Ann. di Ig. Med. Prev. e di comunità 2013, 25, 15-17.

55. Faezipour, M.; Ferreira, S. A system dynamics perspective of patient satisfaction in healthcare. Procedia Comput. Sci. 2013, 16, 148-156. [CrossRef]

56. Dohlman, E. The importance of a policy coherence lens for implementing the Sustainable Development Goals. In Debate the Issues: New Approaches to Economic Challenges; OECD Publishing: Paris, France, 2016.

57. Browning, H.W.; Torain, D.J.; Patterson, T.E. A Six-Part Model for Adapting and Thriving During a Time of Transformative Change. Cent. Creat. Leadersh. 2011, 1-20. 
58. Okpala, P. Balancing Quality Healthcare Services and Costs Through Collaborative Leadership. J. Healthc. Manag. 2018, 63, e148-e157. [CrossRef]

59. Shrivastava, P.; Guimarães-Costa, N. Achieving environmental sustainability: The case for multi-layered collaboration across disciplines and players. Technol. Forecast. Soc. Change 2017, 116, 340-346. [CrossRef]

60. Chen, L.; Zhao, X.; Tang, O.; Price, L.; Zhang, S.; Zhu, W. Supply chain collaboration for sustainability: A literature review and future research agenda. Int. J. Prod. Econ. 2017, 194, 73-87. [CrossRef]

61. Scheirer, M.A.; Hartling, G.; Hagerman, D. Defining sustainability outcomes of health programs: Illustrations from an on-line survey. Eval Progr. Plann 2008, 31, 335-346. [CrossRef] [PubMed]

62. Stirman, S.W.; Kimberly, J.; Cook, N.; Calloway, A.; Castro, F.; Charns, M. The sustainability of new programs and innovations: a review of the empirical literature and recommendations for future research. Implement. Sci. 2012, 7, 17. [CrossRef] [PubMed]

63. Burnap, P.R.; Spasic, I.; Gray, W.A.; Hilton, J.C.; Rana, O.F.; Elwyn, G. Protecting patient privacy in distributed collaborative healthcare environments by retaining access control of shared information. In Proceedings of the 2012 International Conference on Collaboration Technologies and Systems (CTS), Denver, CO, USA, 21-25 May 2012; pp. 490-497.

64. Arcangelo, V.; Fitzgerald, M.; Carroll, D.; Plumb, J. Collaborative care between nurse practitioners and primary care physicians. Prim Care 1996, 23, 103-113. [CrossRef]

65. Rush, B.; Tyler, P.D.; Stone, D.J.; Geisler, B.P.; Walley, K.R.; Celi, L.A. Outcomes of Ventilated Patients with Sepsis Who Undergo Interhospital Transfer: A Nationwide Linked Analysis. Crit. Care Med. 2018, 46, e81-e86. [CrossRef]

66. Khan, M.; Hussain, M.; Gunasekaran, A.; Ajmal, M.M.; Helo, P.T. Motivators of social sustainability in healthcare supply chains in the UAE-Stakeholder perspective. Sustain. Prod. Consum. 2018, 14, 95-104. [CrossRef]

67. Greenfield, S.; Kaplan, S.; Ware, J.E. Expanding patient involvement in care: Effects on patient outcomes. Ann. Intern. Med. 1985, 102, 520-528. [CrossRef]

68. Montori, V.M.; Gafni, A.; Charles, C. A shared treatment decision-making approach between patients with chronic conditions and their clinicians: The case of diabetes. Heal. Expect. 2006, 9, 25-36. [CrossRef]

69. Joosten, E.A.G.; DeFuentes-Merillas, L.; de Weert, G.H.; Sensky, T.; van der Staak, C.P.F.; de Jong, C.A.J. Systematic Review of the Effects of Shared Decision-Making on Patient Satisfaction, Treatment Adherence and Health Status. Psychother. Psychosom. 2008, 77, 219-226. [CrossRef]

70. Bartunek, J.M. Intergroup relationships and quality improvement in healthcare. BMJ Qual. Saf. 2011, 20. [CrossRef]

71. Fisher, M.D.; Weyant, D.; Sterrett, S.; Ambrose, H.; Apfel, A. Perceptions of interprofessional collaborative practice and patient/family satisfaction. J. Interprofessional Educ. Pract. 2017, 8, 95-102. [CrossRef]

72. Nair, D.M.; Fitzpatrick, J.J.; McNulty, R.; Click, E.R.; Glembocki, M.M. Frequency of nursephysician collaborative behaviors in an acute care hospital. J. Interprof. Care 2012, 26, 115-120. [CrossRef] [PubMed]

73. Berendsen, A.J.; Benneker, W.H.G.M.; Schuling, J.; Rijkers-Koorn, N.; Slaets, J.P.J.; Meyboom-De Jong, B. Collaboration with general practitioners: Preferences of medical specialists - A qualitative study. BMC Health Serv. Res. 2006, 6. [CrossRef] [PubMed]

74. Raza, M. Collaborative Healthcare Research: Some ethical considerations. Sci. Eng. Ethics 2005, 11, 177-186. [CrossRef]

75. Gu, D.; Reynolds, K.; Duan, X.; Xin, X.; Chen, J.; Wu, X.; Mo, J.; Whelton, P.K.; He, J. Prevalence of diabetes and impaired fasting glucose in the Chinese adult population: International Collaborative Study of Cardiovascular Disease in Asia (InterASIA). Diabetologia 2003, 46, 1190-1198. [CrossRef]

76. Word Health Organization (WHO). People-Centred Health Care: A Policy Framework; Word Health Organization: Tokyo, Japan, 2007; ISBN 9789290613176.

77. Boswell, J.; Settle, C.; Dugdale, A. Who Speaks, and in What Voice? The Challenge of Engaging 'The Public' in Health Policy Decision-Making. Public Manag. Rev. 2015, 17, 1358-1374. [CrossRef]

78. Dabelko, G. Turning up the volume on the science-practice interface in global change. IHDP Updat. Newsl. Int. Hum. Dimens. Program. Glob. Environ. Chang. 2006, 3-4, 1-5.

79. Vlek, C.; Steg, L. ? Human Behavior and Environmental Sustainability: Problems, Driving Forces, and Research Topics. J. Soc. Issues 2007, 63, 1-19. [CrossRef] 
80. Al-Dweik, G.; Al-Daken, L.I.; Abu-Snieneh, H.; Ahmad, M.M. Work-related empowerment among nurses: Literature review. Int. J. Product. Qual. Manag. 2016, 19, 168-186. [CrossRef]

81. Wang, Y.; Wan, Q.; Guo, J.; Jin, X.; Zhou, W.; Feng, X.; Shang, S. The influence of effective communication, perceived respect and willingness to collaborate on nurses' perceptions of nurse-physician collaboration in China. Appl. Nurs. Res. 2018, 41, 73-79. [CrossRef]

82. Lomi, A.; Mascia, D.; Vu, D.Q.; Pallotti, F.; Conaldi, G.; Iwashyna, T.J. Quality of care and interhospital collaboration: A study of patient transfers in Italy. Med. Care 2014, 52, 407-414. [CrossRef] [PubMed]

83. Sancha, C.; Gimenez, C.; Sierra, V. Achieving a socially responsible supply chain through assessment and collaboration. J. Clean. Prod. 2016, 112, 1934-1947. [CrossRef]

84. Awan, U. Effects of buyer-supplier relationship on social performance improvement and innovation performance improvement. Int. J. Appl. Manag. Sci. 2019, 11, 21. [CrossRef]

85. Awan, U.; Kraslawski, A.; Huiskonen, J. The impact of relational governance on performance improvement in export manufacturing firms. J. Ind. Eng. Manag. 2018, 11. [CrossRef]

86. Reeves, S.; Pelone, F.; Harrison, R.; Goldman, J.; Zwarenstein, M. Interprofessional collaboration to improve professional practice and healthcare outcomes. Cochrane Database Syst. Rev. 2017, 2017. [CrossRef] [PubMed]

87. Koerner, B.L.; Cohen, J.R.; Armstrong, D.M. Collaborative Practice and Patient Satisfaction. Eval. Health Prof. 1985, 8, 299-321. [CrossRef] [PubMed]

88. Shridharani, S.M.; Magarakis, M.; Manson, P.N.; Rodriguez, E.D. Psychology of plastic and reconstructive surgery: A systematic clinical review. Plast. Reconstr. Surg. 2010, 126, 2243-2251. [CrossRef] [PubMed]

89. Mulkens, S.; Bos, A.E.R.; Uleman, R.; Muris, P.; Mayer, B.; Velthuis, P. Psychopathology symptoms in a sample of female cosmetic surgery patients. J. Plast. Reconstr. Aesthetic Surg. 2012, 65, 321-327. [CrossRef]

90. Sarwer, D.B.; Wadden, T.A.; Pertschuk, M.J.; Whitaker, L.A. The psychology of cosmetic surgery: a review and reconceptualization. Clin. Psychol. Rev. 1998, 18,1-22. [CrossRef]

91. Zwarenstein, M.; Goldman, J.; Reeves, S. Interprofessional collaboration: effects of practice-based interventions on professional practice and healthcare outcomes. Cochrane Database Syst. Rev. 2009, 3, CD000072.

(C) 2020 by the authors. Licensee MDPI, Basel, Switzerland. This article is an open access article distributed under the terms and conditions of the Creative Commons Attribution (CC BY) license (http://creativecommons.org/licenses/by/4.0/). 